\title{
TRANSFER COSTS, SPATIAL ARBITRAGE AND TESTING \\ FOR FOOD MARKET INTEGRATION
}

\author{
Bob Baulch
}

Conventional tests for food market integration ask often misleadingly, whether prices in different locations move together. This paper develops an alternative methodology, the parity bounds model (PBM), which uses information on transfer costs in addition to food prices to assess the efficiency of spatial arbitrage. Monte Carlo experiments using data generated by a point-space spatial price equilibrium model show the PBM to be statistically reliable. An application to Philippine rice markets demonstrates that the PBM detects efficient arbitrage when other tests do not.

Key words: market integration, parity bounds, switching regression model

The author is a Fellow of the Institute of Development Studies, University of Sussex, Falmer, Brighton, BN1 9RE, United Kingdom. He thanks Simon Maxwell, Anne Peck, Jeffrey Williams, Adrian Wood and two anonymous reviewers for helpful comments on earlier drafts of this paper. The support of the International Rice Research Institute during fieldwork in the Philippines is gratefully acknowledged. 
The issue of market integration lies at the heart of many contemporary debates concerning market liberalization, price policy and parastatal reform in developing country food markets. Integration of food markets is also a precondition for effective reform in many of the former centrally planned economies. Without spatial integration of markets, price signals will not be transmitted from urban food deficit to rural food surplus areas, prices will be more volatile, agricultural producers will fail to specialize according to long-term comparative advantage, and the gains from trade will not be realized.

Many studies have been devoted to testing for market integration but nearly all of these studies approach the issue of market integration indirectly. Rather than examining transportation systems, interviewing traders, tracking shipments and looking for unexploited arbitrage opportunities, most researchers have used time-series econometrics applied to observed food prices. Despite widespread recognition of the inferential dangers in using measures of price correlation to test for market integration (Blyn; Harriss), more recent timeseries techniques involving Granger causality (Gupta and Mueller), error-correction (Ravallion) and cointegration (Alexander and Wyeth) are still based on assessing the co-movement of food prices. All such conventional tests rely on price data alone and fail to recognize the pivotal role played by transfer costs. Many researchers also make erroneous assumptions concerning the continuity of trade flows between markets and the nature of price formation in multi-market systems. In consequence, food markets that are well-functioning are often diagnosed as exhibiting incomplete and/or lagged price adjustment (Baulch). 
If time series were available on trade flows and transfer costs in addition to nominal food prices, problems with conventional tests could be easily circumvented. Indeed, testing for the efficiency of spatial arbitrage would reduce to a series of repetitive arithmetic calculations of whether trade occurred whenever the intermarket price differential equalled or exceeded transfer costs. Unfortunately, time series data on trade flows and transfer costs are rarely available to the food price analyst and, even when they are, such data are usually not of the same periodicity as the available food price data. Furthermore, it is inadvisable to estimate transfer costs based on inter-market price differentials when trade flows between two markets are infrequent but occur regularly between each of the two and a third market. In such circumstances, price differentials between the first two markets do not reflect the cost of moving produce between them. Intermarket price spreads may also reflect factors other than pure transfer costs (such as the effect of government controls on produce flows, transportation bottlenecks, or oligopolistic pricing).

Transfer costs, however, should not be disregarded in assessing food market integration. Accurate information on the different components of transfer costs at a single point in time is usually available to the food price analyst from structure-conduct-performance studies or from interviews with traders. At this point in time, there will be little ambiguity about the arbitrage relationships connecting markets since the only element of transactions costs that cannot be measured with precision is the trader's margin. Transfer costs in other periods obviously will vary over time, so an extrapolation from observed transfers costs in one period will be subject to inaccuracies. But as long as care is taken to ensure that no significant element of transfer costs is omitted from the calculation for the single period, the extrapolation of transfer costs to other periods provides a useful starting estimate of transfer costs over the whole time series.

Accordingly, this paper develops and tests the statistical reliability of a new methodology of testing for food market integration: the parity bounds model (PBM). This model extends earlier work on stochastic frontier and switching regression models (Aigner, Lovell and Schmidt; Spiller and Wood; Sexton, Kling and Carman) by using explicit information on transfer costs at a single point in time, in addition to nominal food prices, to 
assess the efficiency of inter-market arbitrage for each period in the sample. The model takes explicit account of the possibility of discontinuous trade between markets, the simultaneous determination of prices, and the statistical problems posed by common trends_especially by non-stationary and cointegrated time series. It also allows transfer costs to vary between periods, makes no implicit assumptions concerning the nature of marketing margins, and may be estimated using time series that are incomplete_as is often the case with food price series in developing countries.

The next section describes the problems associated with conventional approaches to testing market integration while the third section outlines the specification of the PBM. Monte Carlo experiments are then used to assess the statistical reliability of the PBM employing price and trade flow data generated by a point-space model of spatial price equilibrium with both production shocks and general price inflation. The PBM is shown to be able to detect violations of the spatial arbitrage conditions with a high degree of accuracy when estimated with sample sizes that are typical of the short food price series available in most developing countries. Finally, the PBM is applied to wholesale rice markets in the Philippines, and the results are contrasted with those of conventional tests for market integration. 


\section{Problems with Conventional Approaches to Testing Food Market Integration}

Techniques for testing market integration have come a long way since the days when Jones and Lele first used bi-variate correlation coefficients to describe the behavior of staple food prices in Nigeria and India. Considerable progress has been made in designing test procedures that take account of common trends and the non-stationarity of food price series. Some advances also have been made in designing tests that account for the endogeneity of food prices. But none of the current approaches to testing market integration has challenged the basis of the correlation coefficients approach: that market integration can be discerned by assessing the underlying comovement of prices and without reference to transfer costs.

Two markets may be said to be spatially integrated if, when trade takes place between them, price in the importing market equals price in the exporting market plus the transportation and other transfer costs involved in moving food between them. ${ }^{1}$ Put differently, if $P_{t}^{i}$ denotes the price of food in the exporting market in period $t, P_{t}^{j}$ denotes the contemporaneous price of food in the importing market, and $K_{t}^{i j}$ denotes transfer costs in the same period, then whenever

$$
P_{t}^{i}+K_{t}^{i j}=P_{t}^{j}
$$

trade occurs. But if

$$
P_{t}^{i}+K_{t}^{i j}>P_{t}^{j}
$$

then there is no incentive to trade. Equations (1) and (2) are known in the literature as the spatial arbitrage conditions and both are consistent with food market integration. Market integration does not itself, however, imply that food markets are competitive. The spatial 
arbitrage conditions are also consistent with such oligopolistic pricing practices as basing point pricing (Faminov and Benson).

Existing approaches to testing market integration may be divided into two broad categories. Approaches such as the "Law of One Price" (Richardson) and the Ravallion model (Ravallion) are based on testing for the perfect co-movement of prices. These tests assume that if markets are integrated, price changes in one market will be transmitted on a one-for-one basis to other markets either instantaneously (the Law of One Price and Ravallion's tests for short-run integration) or over a number of observations (Ravallion's test for long-run integration). Unless, however, trade flows occur between the two markets under consideration in every period, demand and supply shocks cannot be guaranteed to cause one-for-one co-movement in prices. Furthermore, non-random variations in transfer costs may cause the Law of One Price and Ravallion model to reject market integration even when the spatial arbitrage conditions always hold. Implementation of these tests also requires a choice between absolute or proportional marketing margins as a maintained hypothesis and, when ordinary least squares estimation is used, the assumption that prices in one market are exogenously determined is required.

Other approaches, such as Granger causality (Gupta and Mueller) and cointegration (Alexander and Wyeth; Dercon), test for more general notions of equilibrium. These tests allow for price co-movement to be less than perfect, allow for prices to be simultaneously determined, and permit seasonal variations in transfer costs. But these tests ignore transfer costs and assume a linear relationship between market prices, which is inconsistent with the discontinuities in trade implied by the spatial arbitrage conditions. They, therefore, are consistent with situations in which the spatial arbitrage conditions are systematically violated 
(Baulch) and should be regarded as neither necessary nor sufficient conditions for market integration (Barrett). ${ }^{2}$

Monte Carlo analysis indicates that the statistical reliability of both categories of market integration tests is low. Baulch reports that hypothesis tests for short-run market integration, based on the Law of One Price and the Ravallion model, were performed on simulated price data from markets that were instantaneously integrated by construction, and that they were rejected more than twice as often as they should be. In contrast, the Granger causality and cointegration approaches were unable to distinguish integrated from independent markets when both were subject to a common, exogenous inflationary process. In short, conventional approaches to testing market integration place the food price analyst in a dilemma. Some tests are too strong to detect market integration and others are too weak. None attempt to compare time series of observed price differentials with transfer costs, although this would seem to be the obvious method of testing for market integration. Indeed, no conventional tests make use of any information about actual transfer costs. The assumptions in the conventional approaches to testing market integration and their statistically driven definitions of market integration, therefore, are inappropriate to most real world food markets.

\section{Motivation and Specification of the Parity Bounds Model}

Transfer costs (comprising transportation, loading and unloading costs, and trader's normal profit) determine the parity bounds within which the prices of a homogenous commodity in two geographically distinct markets can vary independently. When transfer costs equal the intermarket price differential (or spread) and there are no impediments to trade between markets, trade will cause prices in the two markets to move on a one-for-one basis and the spatial arbitrage conditions are binding. When transfer costs exceed the inter-market spread, trade will not occur and the spatial arbitrage conditions will not be binding. When spreads exceed transfer costs, the spatial arbitrage conditions are violated whether or not trade occurs. Violation of the spatial arbitrage conditions indicates that there are impediments to trade between markets and 
should be viewed as primae facie evidence of a lack of market integration.

Accordingly, the parity bounds model (PBM) developed in this paper assesses the extent of market integration by distinguishing among three possible trade regimes:

$\underline{\text { Regime 1: }}$ at the parity bounds (in which spatial price differentials equal transfer costs);

Regime 2: inside the parity bounds (in which price differentials are less than transfer

costs); and

Regime 3: outside the parity bounds (in which price differentials exceed transfer costs).

When production and consumption are specialized_so that production of food occurs in different geographical locations from where it is consumed (i.e., there is no on-farm consumption)_only regime 1 is consistent with market integration. But when production and consumption are nonspecialized_as is usually the case in developing country food markets_both regimes 1 and 2 are consistent with the spatial arbitrage conditions and market integration. In either case, regime 3 is inconsistent with integration, so that the higher the incidence of regime 3 , the lower is the extent of market integration.

If time-series data were available on transfer costs, in addition to nominal food prices, dividing observations into these three regimes could be performed by a series of repetitive arithmetic calculations. Each period's observed transfer costs could be deducted from that period's inter-market price differential and the number of observations that were zero (regime 1), negative (regime 2) or positive (regime 3) could be recorded. But, as noted above, time-series data on transportation charges and the other elements of traders' transfer costs are rarely available to the food price analyst. If, however, intermarket price spreads can be compared with exact information on transfer costs obtained from a structure-conduct-performance study or by interviewing traders, it is possible to establish probablistic limits within which the spatial arbitrage conditions are likely to be binding in other periods. This is the central idea behind the parity bounds model.

In situations where food prices are non-stationary, as is usually the case, the probablistic limits (or confidence interval) for the spatial arbitrage conditions can be established in two 
stages. First, the single period information on transfer costs is extrapolated into a time series by deflating it by the consumer price index (or some other suitable measure of the trend in the general price level). ${ }^{3}$ This stage allows the single period information on transfer costs to be compared with the inter-market price differential in other periods. Second, maximum likelihood techniques are used to determine the upper and lower parity bounds within which the extrapolated nominal transfer cost series are likely to vary based on the magnitude of observed price differentials. Figure 1 illustrates the upper and lower parity bounds defined by the confidence interval around extrapolated transfer costs, and how this divides the inter-market price spread into the PBM's three regimes.

More formally, the deviation of the inter-market price spread from extrapolated transfer costs in any period may be decomposed into three components: a symmetric error term with mean zero $\left(e_{t}\right)$ applying to transfer costs plus two error terms truncated from above at zero $\left(u_{t}\right.$ and $v_{t}$ ) which are subtracted or added according to whether price differentials are inside or outside the parity bounds. The first error term $\left(e_{t}\right)$ allows transfer costs to vary between periods, in response to seasonality or changing capacity utilization in the transportation sector. The second error term $\left(u_{t}\right)$ captures the extent to which price differentials fall short of the parity bounds when there is no incentive to trade. The size of $u_{t}$ depends on the relative imbalance between demand and supply in individual markets. The third error term $\left(v_{t}\right)$ measures by how much price differentials exceed transfer costs when the spatial arbitrage conditions are violated. This term shows the extent to which markets are prevented from trading because of transportation bottlenecks, oligopsonistic pricing practices, government controls on produce flows or other impediments to the movement of goods between markets.

Utilizing a result derived by Weinstein for the density of a normal plus half normal distribution, and following Sexton, Kling and Carman, the likelihood function for the PBM may be specified as:

$$
\left.L=\prod_{t=1}^{T}\left[\lambda_{1} f_{t}^{1}+\lambda_{2} f_{t}^{2}+\left(1-\lambda_{1}-\lambda_{2}\right) f_{t}^{3}\right)\right]
$$


where

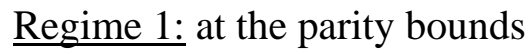

$$
f_{t}^{l}=\frac{1}{\sigma_{e}} \phi\left[\frac{Y_{t}-K_{t}}{\sigma_{e}}\right]
$$

Regime 2: inside the parity bounds

$$
f_{t}^{2}=\left[\frac{2}{\left(\sigma_{e}^{2}+\sigma_{u}^{2}\right)^{1 / 2}}\right] \phi\left[\frac{\left(Y_{t}-K_{t}\right)}{\left(\sigma_{e}^{2}+\sigma_{u}\right)^{1 / 2}}\right]\left[1-\Phi\left[\frac{-\left(Y_{t}-K_{t}\right) \sigma_{e} / \sigma_{u}}{\left(\sigma_{e}^{2}+\sigma_{u}^{2}\right)^{1 / 2}}\right]\right]
$$

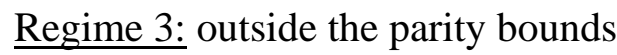

$$
f_{t}^{3}=\left[\frac{2}{\left(\sigma_{e}^{2}+\sigma_{v}^{2}\right)^{1 / 2}}\right] \phi\left[\frac{\left(Y_{t}-K_{t}\right)}{\left(\sigma_{e}^{2}+\sigma_{v}^{2}\right)^{1 / 2}}\right]\left[1-\Phi\left[\frac{\left(Y_{t}-K_{t}\right) \sigma_{e} / \sigma_{v}}{\left(\sigma_{e}^{2}+\sigma_{v}^{2}\right)^{1 / 2}}\right]\right]
$$

Here $\lambda_{1}$ and $\lambda_{2}$ denote the probabilities for regimes 1 and 2, and $Y_{t}$ represents the absolute value of the natural logarithm of the price spread between markets $i$ and $j$ in period $t$ (i.e., $\left.Y_{t}=\ln \left\{/ P_{t^{-}}^{i} P_{t}^{j} /\right\}\right) ; \sigma_{\mathrm{e}}, \sigma_{\mathrm{u}}$ and $\sigma_{\mathrm{v}}$ are the standard deviations of the three error terms $e_{t}, u_{t}$ and $v_{t}$ described above; $K_{t}$ is the logarithm of nominal transfer costs in period $t$, while $\varphi($.$) and \Phi($. denote the standard normal density and distribution functions. To obtain probability estimates for the three regimes of the PBM, the logarithm of this function may be maximized numerically with respect to $\lambda_{1}, \lambda_{2}, \sigma_{\mathrm{e}}, \sigma_{\mathrm{u}}$ and $\sigma_{\mathrm{v}}$ using the David-Fletcher-Powell (or some other suitable) algorithm. ${ }^{4}$

This specification differs from that of Sexton, Kling and Carman in three ways. First, the transfer costs series $\left(\mathrm{K}_{\mathrm{t}}\right)$ is an exogenously determined series, extrapolated from known transfer costs in a single time period, rather than an endogenously estimated parameter. This facilitates accurate sample separation between regimes and avoids the difficulties with estimating transfer costs based on inter-market price spreads noted above. Second, the half normal error terms in the likelihood functions for regimes 2 and 3 are allowed to have different 
variances. It does not seem reasonable to force the variances for the two regimes to be equal, as Sexton, Kling and Carman do. Third, price spreads were expressed in terms of the log of the absolute intermarket price spread forcing transfer costs to be symmetric (i.e., that it costs on average as much to ship one ton of produce from market $i$ to market $j$, as from $j$ to $i$ ). This is clearly an unrealistic assumption but greatly facilitates the maximization of the PBM's likelihood function and does not affect its accuracy unless seasonal reversals in agricultural trade flows actually occur. ${ }^{5}$

For illustrative purposes, the results of the application of the PBM to the data underlying figure 1 are shown in table $1 .{ }^{6}$ The estimate of $\lambda_{1}$ shows that price differentials are at their parity bounds in $88.1 \%$ of the observations. Similarly, the estimate for $\lambda_{2}$ indicates that price spreads are inside the parity bounds in another $5.6 \%$ of the observations. Since the probability estimates for the three regimes must sum to one, price differentials must be outside their parity bounds in $6.3 \%$ (i.e., 1.0-0.881-0.056) of the observations. This would indicate a modest degree of market disintegration between markets $i$ and $j{ }^{7}$ The relative sizes of the three variance terms together with their standard errors indicate that, as one would expect, price spreads are much more volatile when outside or inside the parity bounds than when at them. The t-statistics indicate that all parameter estimates are significantly different from zero at the $1 \%$ level.

These parameter estimates provide much richer information on the extent of market integration than the dichotomous hypothesis tests of the conventional approaches of testing for market integration. In the latter case, the food price analyst is restricted to "accepting" or rejecting a null hypothesis (possibly nested) at some predetermined significance level. But the parity bounds model allows for markets to be integrated in some periods but not in others. Statistical hypotheses tests for the presence of market integration still can be conducted by testing the null hypothesis that $\lambda_{1}+\lambda_{2}=1$. But the food price analyst also may choose to avoid the "accept"/reject nature of such test procedures by focusing on the magnitude of the regime probabilities themselves. The parameter $\lambda_{3}$, for example, shows how frequently the spatial arbitrage conditions are violated and may be interpreted as a index of market efficiency (in 
which values close to zero indicate that the spatial arbitrage is usually efficient).

\section{Monte Carlo Results}

To assess the statistical reliability of the PBM, a series of Monte Carlo experiments were performed using time series generated by a spatial price equilibrium model in the point-space tradition of Samuelson, and Takayama and Judge. In this model, five discontinuous regions with identical demand characteristics but different (and stochastic) levels of supply trade a homogeneous commodity under competitive marketing conditions. Spatial price equilibrium is established when all arbitrage opportunities between regions have been exhausted, so that price in importing regions equals price in the regions which export to them plus transfer costs. The direction and magnitude of trade flows between regions varies from period to period according to imbalances in excess demand, which are in turn driven by a series of uncorrelated harvest shocks occurring once a period in each region. All prices generated by the model experience a common upward trend due to an exogenously determined, stochastic inflationary process driven by macro policy. The inflationary process affects all regions equally and renders their food prices series non-stationary in levels but stationary in first differences (i.e., $I(1)){ }^{8}$

Three alternative trading scenarios for the spatial price equilibrium model_integrated, partially integrated and independent markets_are considered in the Monte Carlo simulations. In the first scenario, the "integrated markets case", there are no impediments to trade between markets and the spatial arbitrage conditions hold in $100 \%$ of the observations. This does not, however, mean that markets always trade; sometimes price differentials are less than transfer costs so there is no incentive to trade. In the second scenario, the "partially integrated markets case", an impediment to trade occurs in $10 \%$ of the observations. Readers may find it helpful to think of typhoons, heavy rains, government controls on produce flows, or periodic road blocks as the cause of these impediments. ${ }^{9}$ The third scenario, the "independent markets case", assumes that markets are prevented from trading with each other even though price differentials always exceed transfer costs. Prices in each market are therefore exogenously determined and 
price differentials are outside the parity bounds in $100 \%$ of the observations.

Tables 2 and 3 shows the mean, maximum and minimum biases for each of the regime probabilities $(\lambda s)$ when the PBM is estimated using data generated by these three variants of the spatial price equilibrium model described above. One-thousand replications, each with either 120 or 60 observations, were performed for each trading scenario. ${ }^{10}$ Bias is defined as the estimated minus the true regime probabilities $\left(\mathrm{i}_{\mathrm{i}}-\lambda_{\mathrm{i}}\right)$. So, if the PBM estimated the regime probabilities without error, all biases would be equal to zero. The mean bias entries therefore show the average discrepancy between the PBM's estimates of the regime probabilities and the true incidence of trade in one thousand replications of the PBM model. Negative mean biases indicate that the PBM under-estimates the underlying regime probabilities on average; positive biases indicate it over-estimates them.

Tables 2 and 3 shows that the PBM is able to distinguish between integrated and independent markets rather successfully. When applied to the integrated markets case (where there are only two regimes in the underlying data generation mechanism), the mean bias for regime 3 is tiny (7.3 E-07 and 4.0E-08, respectively). Similarly, when it is applied to the independent markets case (where there is only one regime in the underlying data generation mechanism), the mean biases for regimes 1 and 2 are each one-tenth of one percent. The largest mean biases occur in the partially integrated markets case but even here they are relatively small. With a sample size 120 observations (table 2), the mean bias for the crucial regime 3 is 0.0025 , compared to 0.035 with 60 observations (table 3 ). Since by construction the spatial arbitrage conditions are violated in $10 \%$ of the observations in this case, on average the parity bounds model estimates the probability of violation of the arbitrage conditions to within $2.5 \%$ (i.e., $0.0025 / .01 \times 100$ for table 2 ) or $3.5 \%$ (table 3 ) of their true values.

For individual replications, higher or lower biases naturally occur. The range of maximum and minimum biases occurring in every Monte Carlo experiment also are shown in tables 2 and 3. However, a more comprehensive picture of the magnitude of the biases is given by plotting histograms of their values for all one thousand replications. 
These show that extreme biases occur very rarely. In the integrated markets case, for example, most biases for regime 1 are in the -0.032 to 0.015 range, those for regime 2 range from -0.015 to 0.04 , while those for regime 3 are negligible.

The rare occurrence of some points of extreme biases together with the failure to attain convergence in some replications (see the final column of tables 2 and 3) points to a distinctive feature of the PBM. In common with all stochastic switching regression models, the PBM is in the class of maximum likelihood estimators which are unbounded in parameter space. Such models have likelihood functions with spikes at the edges of their parameter space, and where gradients tend toward singularity. Such spikes either cause the non-convergence of the solution algorithm (because their gradients cannot be evaluated) or for convergence to occur at a local rather than a global maximum (leading to the rare occurrences of the points of extreme bias noted above). These convergence problems have two practical implications for the implementation of the PBM. First, convergence problems cannot always be solved by choosing a new set of starting values or by using a different maximization algorithm (Quandt). Second, tstatistics in the hundreds or thousands indicate that the edge of the parameter space has been encountered. At such points standard statistical inference becomes invalid because of the local violation of the second regularity condition required for the consistency and asymptotic normality of maximum likelihood estimators (Davidson and MacKinnon).

\section{Empirical Application}

This section applies the PBM to the integration of wholesale rice markets in the Philippines. ${ }^{11}$ This country provides an interesting case study of the practical application of such tests because the uneven geographical and seasonal distribution of rice production and consumption creates a natural tendency to trade within this archipelago. Based on an examination of the regional demand-supply balance and pattern of inter-regional trade, five of the Philippines's twelve regions plus Metro Manila have been selected for inclusion in the analysis. Region II (Northern Luzon), Region III (Central Luzon) and Region VI (Western Visayas) are the country's principal 
rice surplus regions. Metro Manila, the national capital, and Region VII (Central Visayas) are the principal rice deficit regions. Region IX (Western Mindanao) is a relatively isolated area that is close to self-sufficiency in rice production. The price data used in the empirical analysis are the monthly wholesale price series for special grade rice collected by the Philippine Bureau of Agricultural Statistics between January 1980 and June 1993. Application of the augmented Dickey-Fuller test shows all these series to be non-stationary in levels but stationary in first differences. $^{12}$

Inter-island shipping provides the major mode of transportation between these regions, although road transport is also important for the transportation of rice from regions II and III to Metro Manila. Several shipping lines compete on all major inter-island shipping routes with the exception of Iloilo (Region VI) to Cebu (Region VII) where one shipping line has the monopoly. There are twice or thrice weekly services between most major ports with daily services between Manila, Cebu and Iloilo. Shipping freight rates do not vary according to the direction of shipment and are regulated, along with wharfage and arrastre charges, by the Philippine national authorities. It, therefore, was possible to establish the exact unit shipping costs between regions at a single point in time by summing the approved freight rate for "basic class commodities" (which includes rice) with the wharfage, loading and unloading charges that are set on a port by port basis. For markets connected by road, where haulage rates are not controlled, unit freight costs were established by interviewing traders concerning the rates they paid for trucking, loading and unloading using the most commonly used truck/trailer combination. To these unit freight costs estimates was added the five to eight peso margin revealed in a survey of traders conducted by the author in the summer of 1993. In the absence of an index of transportation costs, the resulting market specific transfer costs were then extrapolated into a series by deflating by the All Philippine Consumer Price Index.

The results of the maximum likelihood estimation of the PBM are shown in table 8. If, as suggested in the second section, the sum of the probabilities of regimes 1 and 2 is interpreted 
as the probability of market integration, the results indicate that Philippine rice markets are integrated within a single data period almost $100 \%$ of the time. These findings are consistent with the trader survey conducted by the author, the existence of good telecommunication links between all the markets considered, and the frequency of shipping services relative to the monthly periodicity of the price data used. ${ }^{13}$ However, the significant probabilities for regime 2 for all markets except regions VI and VII indicate that there are discontinuities over time in trade flows between regions. ${ }^{14}$ Such discontinuities are in line with inter-island shipping records and also with the results of the author's trader survey, which indicated that wholesalers in demand deficit areas switch between alternative sources of supply in response to changing arbitrage opportunities.

The PBM results are, however, at odds with the results of conventional tests for market integration reviewed in the second section. Using the same monthly regional price data, these tests indicate that Philippine rice prices are cointegrated and simultaneously determined but with a lag of between one and two months. The estimation of long-run multipliers (which are all significantly different from one) and the rejection of the Law of One Price, Ravallion's test for short-run market integration at the one-percent level between all market pairs indicates that price adjustment is not one-for-one. ${ }^{15}$ The usual interpretation of such results, which are similar to other studies of food market integration conducted in the Philippines (Mendoza and Rosegrant), is that markets are imperfectly integrated and price adjustment between them is sluggish. However, an alternative explanation of these results is that the failure of conventional tests to detect high levels of market integration is due to their failure to take account of transactions costs and the resulting discontinuity of trade flows between regions. The results of the conventional tests for market integration and the PBM are therefore quite consistent, even though their interpretations appear contradictory. 


\section{Conclusions}

This article has sought to develop and test the statistical reliability of a new methodology of testing for food market integration: the parity bounds model. Unlike conventional approaches to testing market integration, this model recognizes the pivotal role played by transfer costs and the spatial arbitrage conditions. By using information on the level of transfer costs in a single period in addition to nominal food price series, the parity bounds model is able to distinguish between inter-market price spreads that coincide with, are inside, or are outside the parity bounds. This allows the food price analyst to go beyond the conventional tests for market integration based on the co-movement of prices and to recognize that efficient markets may be linked by discontinuous trade flows. The parity bounds model is also consistent with other well-known characteristics of developing country food markets. Its maximum likelihood procedure allows food prices to be simultaneously determined, it allows for transfer costs to vary between periods, and it makes no implicit assumptions concerning the form of traders' marketing margins.

Monte Carlo experiments based on data generated by a stochastic spatial price equilibrium model with sample sizes of sixty and 120 observations demonstrate that the parity bounds model can detect violations of the spatial arbitrage conditions with a high degree of accuracy. An application of the parity bounds model to wholesale rice markets in the Philippines shows that the model detects efficient spatial arbitrage in situations where conventional tests fail to do so because of the existence of discontinuous trade flows.

Three limitations of the PBM, however, must be stressed. First, since only contemporaneous spreads are used in its estimation, it is hard for the PBM to take account of the type of lagged price adjustment postulated by the Granger causality and Ravallion models. It is therefore advisable to estimate the PBM with price data that have been measured at a low frequency (e.g., on a monthly or quarterly basis), in order to allow sufficient time for intermarket arbitrage to occur. Alternatively, if a fixed lag in price adjustment can be specified $a$ priori, it is possible to utilize this in calculating the price spread used in estimating the 
likelihood function.

Second, it is essential that transfer costs are estimated as precisely as possible, as the PBM's estimates of regime probabilities are only as good as the estimate of mean transfer costs used to separate the inter-market price differentials between regimes. Since time series data on traders' transfer costs are usually unavailable, it has been assumed that the food price analyst will be forced to work with transfer costs information for a single period adjusted by the consumer price index or some other measure of general price inflation. If, however, more comprehensive information (e.g., the dates and magnitudes of, possibly seasonal, freight rate changes) these could be incorporated into the calculations of the transfer cost series, $K_{t}$. Serious inaccuracies in the estimation of transfer costs, however, will lead to a wide transaction costs band (high $\sigma_{\mathrm{e}}$ ) or problems with the convergence of the maximum likelihood procedure. ${ }^{16}$ However, incorporation of additional information about transfer costs derived from a single period usually allows the PBM's maximum likelihood procedure to distinguish between regimes rather accurately.

Third, and probably most important, corrective policies do not follow directly from the results of the parity bounds model. Violations of the spatial arbitrage conditions indicate lack of market integration but they do not pin-point its causes. A high incidence of observations outside the parity bounds, for example, could be due to bottlenecks in the transportation sector, oligopolistic pricing by traders, poor transmission of price information, or government controls on produce flows. Similarly, a high incidence of observations within the parity bounds may indicate that transfer costs are prohibitive but also that regions are usually food self-sufficient. The PBM provides the food price analyst with a more reliable procedure of testing for market integration, but a considerable amount of investigative field work is still required to interpret and draw policy implications from its results. The parity bounds model is a complement rather than a substitute to understanding how real markets operate on the ground. 


\section{REFERENCES}

Aigner, D., C. Lovell and P. Schmidt, "Formulations and estimation of stochastic frontier production function models", J. Econometrics 6(1977): 21-37

Alexander, C., and J. Wyeth, "Cointegration and market integration: an application to the Indonesian rice market", J. Dev. Studies 30(January 1994): 303-28

Barrett, C., "Market analysis methods: are our enriched toolkits well-suited to enlivened markets?", Amer. J. Agr. Econ 78(August 1996): 825-829

Baulch, R., "Spatial price equilbrium and food market integration", $\mathrm{PhD}$

dissertation, 1994, Food Research Institute, Stanford

Blyn, G., "Price series correlation as a measure of market integration", Indian J. Agr. Econ. 28(April 1973): 56-59

Davidson, R., and J. MacKinnon, Estimation and Inference in Econometrics, New York: Oxford University Press, 1993

Dercon, S., "On market integration and liberalisation: method and application to Ethiopia", J. Dev. Studies 32(October 1995)

Engle, R., and C. Granger, "Cointegration and error correction: representation, estimation and testing", Econometrica 55(March 1987): 251-276

Fackler, P., "Spatial price analysis: a methodological review", Mimeo, North Carolina State University (April 1996)

Fafchamps, M., and S. Gavian, "The spatial integration of livestock markets in Niger", Journal of African Economies 5(October 1996): 366-405

Faminov, M. and B. Benson, "Integration of spatial markets", Amer. J. Agr. Econ. 72(January 1990): 49-62

GooGoodwin, B., T. Grennes, and M. Wohlgenant, "A revised test of the law of one price using rational price expectations", Amer. J. Agr. Econ. 72(August 1990): 682-693 Gupta, S. and R. Mueller, "Analysing the pricing efficiency in spatial markets; 
concept and application", Euro. Rev. Agr. Econ. 9(1982): 24-40

Hall, B., C. Cummins, and R. Schnake, Time Series Processor Version 4.2 Reference Manual Palo Alto: TSP International, 1991

Harriss, B., "There is method in my madness: or is it vice versa? Measuring agricultural product performance", Food Research Institute Studies 17(1979): 197218

Jones, W.O., "The structure of staple food marketing in Nigeria as revealed by price analysis", Food Research Institute Studies 8(1968): 95-124

Lele, U., "Market integration: a study of sorghum prices in Western India", J. Farm Econ. 49(February 1967): 149-59

Mendoza, M., and M. Rosegrant, "Pricing behaviour in Philippine corn markets: implications for market efficiency", International Food Policy Research Institute Research Report, No 101(1995)

Palaskas, T., and B. Harriss-White, "Testing market integration: new approaches with case study material for the West Bengal Economy", J. Dev. Studies 30 (October 1993): $1-57$

Quandt, R. E., The Econometrics of Disequilibrium, New York: Basil Blackwell (1988)

Ravallion, M., "Testing market integration", Amer. J. Agr. Econ. 68(February 1986): 102-109

Richardson, D., "Some empirical evidence on commodity arbitrage and the law of one price", J. International Econ. 8(1978): 341-51

Samuelson, P., "Spatial price equilibrium and linear programming", Amer. Econ. Rev. 42 (June 1952): 283-303

Sexton, R., C. Kling, and H. Carman, "Market integration, efficiency of arbitrage and imperfect competition: methodology and an application to U.S. celery", Amer. J. Agr. 
Econ. 7(May 1991): 568-580

Spiller, P., and R. Wood, "The estimation of transaction costs in arbitrage models",

J. Econometrics 39(1988): 309-326

Takayama, T., and G. Judge, "Spatial equilibrium and quadratic programming",

Journal Farm Econ. 46(February 1964): 67-93

Weinstein, M., "The sum of values from a normal and truncated normal distribution", Technometrics 6(1964): 104-1055 
1. This is the same definition of market integration as used by Ravallion. Note, however, that some analysts use the term market integration to refer to the frequency with which markets are linked by trade (Fackler).

2. Cointegration is an unnecessary condition for market integration because if transfer costs are non-stationary, arbitrage between two markets may be efficient even when their prices series are not cointegrated. Cointegration is an insufficient condition for market integration because two price series may be cointegrated but their price differential be too small to offset transfer costs. The practical importance of cointegration is not as a test for market integration in its own right but as a pre-test for other econometric tests for market integration (Alexander and Wyeth).

3. Since time-series data on transfer costs are usually unavailable, this discussion assumes that the food price analyst will be forced to work with a single period estimate of transfer costs adjusted for inflation. If, however, more comprehensive information (e.g., dates and magnitude of freight rate charges) were known, they should be incorporated into the transfer costs series, $\mathrm{K}_{\mathrm{t}}$. Seasonal variation in transportation costs also could be incorporated.

4. The distributional assumption of normal and half-normal errors is, of course, questionable. While it seems reasonable to specify a normal distribution for $\mathrm{e}_{\mathrm{t}}$, there is no $a$ priori reason why $u_{\mathrm{t}}$ or $v_{\mathrm{t}}$ should be one-sided. The Monte Carlo results in the third section, however, suggest that the assumption of half-normality does not bias the results of the PBM seriously.

5. If seasonal reversals in agricultural trade flows occur and transfer costs are asymmetric (due, for example, to backloading), it is necessary to add another two regimes and a second transfer costs series to the PBM. The model presented here, therefore, should be thought of as the simplest version of the general class of models with non-linear price behavior and exogenous estimates of transfer costs.

6. Estimation of the PBM model was carried out using the ML(HCOV=D,HITER=D) option in TSP version 4.2 (Hall, Cummins and Schnake).

7. A reviewer has noted that an alternative interpretation exists of the PBM model results. The PBM's likelihood function is based on a mixture distribution, which can be viewed as a flexible way to model an unknown probability distribution. Thus, non-zero and significant estimates of $\lambda_{2}$ and $\lambda_{3}$ may result from the distribution of price spreads having fat tails or skewness rather than because of price spreads inside and outside the parity bounds. The Monte Carlo results reported in the third section, however, indicate that the parity bounds model is able to distinguish between trading regimes rather successfully, even when their underlying price spreads are skewed.

8. For further details on the spatial price equilibrium model underlying the data generation mechanism see Baulch.

9. The data in figure 1 correspond to the case of partially integrated markets. 
10. 120 observations corresponds to ten years of monthly price data, which is typical of the short food price time series available in most developing countries.

11. The parity bounds model has also been applied successfully to livestock markets in Niger (Fafchamps and Gavian).

12. Similar results apply for the univariate series in natural logarithms and log differences.

13. Similar results were also obtained using weekly data on wholesale rice prices obtained from the National Food Authority. These results are not reported here because they relate to a much shorter (three-and-a-half year) data period and the existence of numerous missing data points in the weekly price data.

14. The case of regions VI and VII illustrates the difficulties which may arise when the PBM encounters the edge of the parameter space during its maximum likelihood estimation. The author's survey of traders indicates that there are times of the year when the two regions did not trade with each other directly. However, no set of starting values could be found at which the PBM did not "converge" at the edge of the parameter space, indicating continuous trade between this pair of markets.

15. Pairwise tests for cointegration were conducted using the augmented Dickey-Fuller tests between all possible market pairs. The Granger causality and the Ravallion model were estimated in error-correction form with a lag of one to two months using both ordinary least squares and instrumental variable estimation. The Law of One Price was estimated in both first and log-differences using ordinary least squares with correction for first-order serial correlation. See Baulch for further details.

16. Experimentation indicates that the PBM will fail to converge or encounter the edges of the parameter space when transfer costs are over or under-estimated by more than $12.5 \%$. 
Table 1: A Typical Replication of the Parity Bounds Model

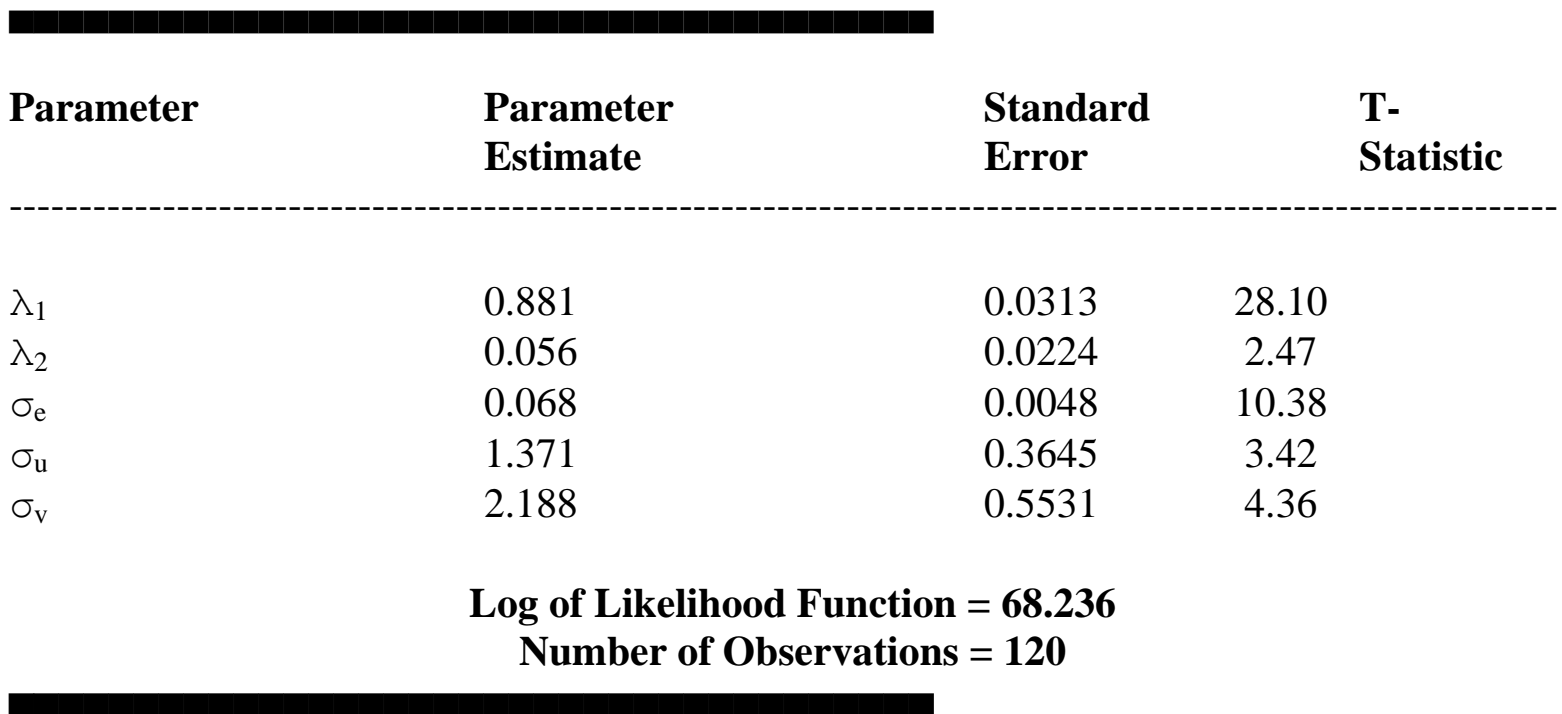


Table 2: Bias of the PBM's Estimated Regime Probabilities (based on 1,000 replications with sample size of 120)

REGIME 1

REGIME 2

REGIME 3

CONVER

-GENCES

\section{Integrated Markets}

$\begin{array}{llll}\text { Mean } & -0.0126 & 0.0126 & 7.3 \mathrm{E}-07 \\ \text { Range } & (-0.049,+0.035) & (-0.034,+0.049) & 998\end{array}$

\section{Partially Integrated Markets}

$\begin{array}{llll}\text { Mean } & -0.0157 & 0.0144 & 0.0025988 \\ \text { Range } & (-0.098,0.027) & (-0.025,+0.093) & (-0.028,+0.062)\end{array}$

\section{Independent Markets}

$\begin{array}{lllll}\text { Mean } & 0.0010 & 0.0010 & -0.0035 & 942 \\ \text { Range } & (+0.001,+0.001) & (+0.001,+0.001) & (-0.027,-0.002)\end{array}$

Notes: $\quad$ Bias $=\left({ }^{\wedge}-\lambda_{i}\right)$. Only regime probabilities that are significant at the $5 \%$ level have been used in the bias calculations. 
Table 3: Bias of the PBM's Estimated Regime Probabilities (based on 1,000 replications with sample size of 60 )

REGIME 1

REGIME 2

REGIME 3

CONVER

-GENCES

\section{Integrated Markets}

$\begin{array}{llll}\text { Mean } & -0.0127 & 0.0135 \quad 4.0 \mathrm{E}-08 & 999 \\ \text { Range } & (-0.082,+0.04) & (-0.04,+0.082)\end{array}$

\section{Partially Integrated Markets}

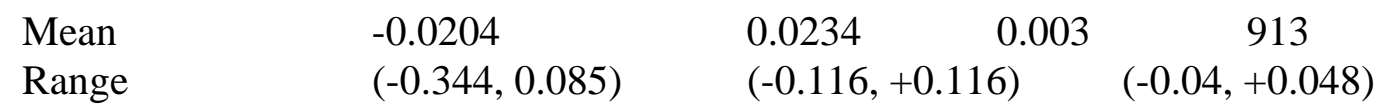

\section{Independent Markets}

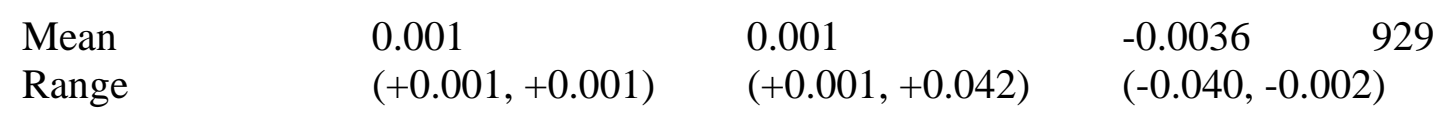

Notes: $\quad$ Bias $=\left({ }^{{ }_{\mathrm{i}}}-\lambda_{\mathrm{i}}\right)$. Only regime probabilities that are significant at the $5 \%$ level have been used in the bias calculations. 
Table 4: The Parity Bounds Model's Estimated Regime Probabilities for Philippine Wholesale Rice Markets

\begin{tabular}{|c|c|c|c|}
\hline & Regime 1 & Regime 2 & Regime \\
\hline Region II-Manila & $\begin{array}{r}0.939 \\
(0.000)\end{array}$ & $\begin{array}{cc}0.061 \\
(0.039) & (0.965)\end{array}$ & 6.3E-06 \\
\hline Region III-Manila & $\begin{array}{r}0.582 \\
(0.000)\end{array}$ & $\begin{array}{c}0.417 \\
(0.000) \\
(0.994)\end{array}$ & $3.1 \mathrm{E}-07$ \\
\hline Manila-Region VII & $\begin{array}{r}0.754 \\
(0.000)\end{array}$ & $\begin{array}{cc}0.246 \\
(0.000) & (0.997)\end{array}$ & $6.6 \mathrm{E}-08$ \\
\hline Manila-Region IX & $\begin{array}{r}0.357 \\
(0.000)\end{array}$ & $\begin{array}{c}0.642 \\
(0.000)\end{array}$ & 2.2E-06 \\
\hline Region VI-Manila & $\begin{array}{r}0.774 \\
(0.000)\end{array}$ & $\begin{array}{cc}0.225 \\
(0.000) & (0.15)\end{array}$ & $3.2 \mathrm{E}-08$ \\
\hline Region VI-Region VII & $\begin{array}{r}0.999 \\
(0.00 *)\end{array}$ & $\begin{array}{c}0.001 \\
\left(0.00^{*}\right) \\
(0.992)\end{array}$ & $1.2 \mathrm{E}-10$ \\
\hline Region VI-Region IX & $\begin{array}{r}0.871 \\
(0.000)\end{array}$ & $\begin{array}{c}0.128 \\
(0.004) \quad(0.992)\end{array}$ & 4.8E-07 \\
\hline Region VII-Region IX & $\begin{array}{r}0.211 \\
(0.005)\end{array}$ & $\begin{array}{cc}0.789 \\
(0.000) & (0.881)\end{array}$ & 0.000 \\
\hline
\end{tabular}

Notes: P-values in parentheses. * indicates that P-values may be invalid as edge of parameter space was encountered during estimation 